\title{
IRE1 $\alpha$ Is a Therapeutic Target for Cystic Fibrosis Airway Inflammation
}

\author{
Emily A. Hull-Ryde ${ }^{1}$, John T. Minges ${ }^{1}$, Mary E. B. Martino ${ }^{1}$, Takafumi Kato ${ }^{1}$, Jacqueline L. Norris-Drouin ${ }^{2}$ \\ and Carla M. P. Ribeiro $1,3,4, * \mathbb{D}$
}

1 Marsico Lung Institute and Cystic Fibrosis Research Center, School of Medicine, University of North Carolina, Chapel Hill, NC 27599, USA; hullryde@email.unc.edu (E.A.H.-R.); john_minges@med.unc.edu (J.T.M.); marybmartino@gmail.com (M.E.B.M.); taka_kato@med.unc.edu (T.K.)

2 Center for Integrative Chemical Biology and Drug Discovery, Eshelman School of Pharmacy, University of North Carolina, Chapel Hill, NC 27599, USA; jnorris@unc.edu

3 Division of Pulmonary Diseases, Department of Medicine, School of Medicine, University of North Carolina, Chapel Hill, NC 27599, USA

4 Department of Cell Biology and Physiology, School of Medicine, University of North Carolina, Chapel Hill, NC 27599, USA

* Correspondence: carla_ribeiro@med.unc.edu

Citation: Hull-Ryde, E.A.; Minges, J.T.; Martino, M.E.B.; Kato, T.; Norris-Drouin, J.L.; Ribeiro, C.M.P. IRE1 $\alpha$ Is a Therapeutic Target for Cystic Fibrosis Airway Inflammation. Int. J. Mol. Sci. 2021, 22, 3063. https://doi.org/10.3390/ijms22063063

Academic Editor:

Nicoletta Pedemonte

Received: 29 January 2021

Accepted: 15 March 2021

Published: 17 March 2021

Publisher's Note: MDPI stays neutral with regard to jurisdictional claims in published maps and institutional affiliations.

Copyright: (c) 2021 by the authors. Licensee MDPI, Basel, Switzerland. This article is an open access article distributed under the terms and conditions of the Creative Commons Attribution (CC BY) license (https:// creativecommons.org/licenses/by/ $4.0 /)$.

\begin{abstract}
New anti-inflammatory treatments are needed for CF airway disease. Studies have implicated the endoplasmic reticulum stress transducer inositol requiring enzyme $1 \alpha$ (IRE1 $\alpha)$ in CF airway inflammation. The activation of IRE1 $\alpha$ promotes activation of its cytoplasmic kinase and RNase, resulting in mRNA splicing of X-box binding protein-1 (XBP-1s), a transcription factor required for cytokine production. We tested whether IRE1 $\alpha$ kinase and RNase inhibition decreases cytokine production induced by the exposure of primary cultures of homozygous F508del CF human bronchial epithelia (HBE) to supernatant of mucopurulent material (SMM) from CF airways. We evaluated whether IRE1 $\alpha$ expression is increased in freshly isolated and native CF HBE, and couples with increased XBP-1s levels. A FRET assay confirmed binding of the IRE1 $\alpha$ kinase and RNase inhibitor, KIRA6, to the IRE1 $\alpha$ kinase. F508del HBE cultures were exposed to SMM with or without KIRA6, and we evaluated the mRNA levels of XBP-1s, IL-6, and IL-8, and the secretion of IL- 6 and IL-8. IRE1 $\alpha$ mRNA levels were up-regulated in freshly isolated CF vs. normal HBE and coupled to increased XBP-1s mRNA levels. SMM increased XBP-1s, IL-6, and IL-8 mRNA levels and up-regulated IL- 6 and IL-8 secretion, and KIRA6 blunted these responses in a dose-dependent manner. Moreover, a triple combination of CFTR modulators currently used in the clinic had no effect on SMM-increased XBP-1s levels coupled with increased cytokine production in presence or absence of KIRA6. These findings indicate that IRE1 $\alpha$ mediates cytokine production in CF airways. Small molecule IRE1 $\alpha$ kinase inhibitors that allosterically reduce RNase-dependent XBP-1s may represent a new therapeutic strategy for CF airway inflammation.
\end{abstract}

Keywords: cystic fibrosis; airway epithelia; airway inflammation; cytokine; unfolded protein response; inositol requiring enzyme $1 \alpha$; KIRA6; CFTR modulators

\section{Introduction}

Cystic fibrosis (CF) pulmonary disease is the culmination of a series of events consequential to mutations in the CF transmembrane conductance regulator (CFTR). Defective CFTR function results in decreased $\mathrm{Cl}^{-}$secretion associated with alterations in sodium transport [1,2], resulting in airway dehydration [3], thickened mucus that accumulates on the airway surface, and impairment of mucociliary clearance [4-6]. These alterations lead to persistent bacterial infection-induced chronic inflammation [7-15], which can harm the airways of CF patients [16]. Indeed, it has been suggested that the CF airway inflammatory response is "excessive" $[17,18]$. 
The specific inflammatory response of $\mathrm{CF}$ airway epithelia is a key contributing factor for the chronically inflamed status of CF airways [19-21]. For instance, CF airway epithelia exhibit persistent activation of nuclear factor- $\mathrm{KB}(\mathrm{NF}-\mathrm{\kappa B})$, elevated production of proinflammatory cytokines, and decreased secretion of anti-inflammatory mediators [22-25]. We have shown that inflammation of airway epithelia promotes expansion of endoplasmic reticulum (ER) $\mathrm{Ca}^{2+}$ stores [26], which can contribute to airway inflammation via amplification of $\mathrm{Ca}^{2+}$-mediated cytokine production [22]. This airway epithelial response is likely beneficial for acute infection in airways with normal mucociliary clearance by helping to clear the infectious insult. In contrast, in obstructed CF airways, the amplification of $\mathrm{Ca}^{2+}$-dependent inflammatory responses resulting from the expansion of $\mathrm{ER} \mathrm{Ca}^{2+}$ stores is likely ineffective in improving the clearance of chronic infection in thickened mucus and could damage the airway walls [22,27].

Increased protein synthesis, including up-regulation of cytokine production resulting from CF airway epithelial inflammation, triggers ER stress, which activates the unfolded protein response (UPR) [28-30]. In mammalian cells, the UPR is comprised by three major pathways: (1) inositol requiring enzyme 1 (IRE1), (2) activating transcription factor 6 (ATF6), and (3) PKR-like ER kinase/pancreatic eIF2 $\alpha$ kinase (PERK). Because our previous studies have revealed that IRE1-dependent signaling is functionally important for airway inflammation [28-30], our research has focused on this UPR pathway. IRE1 exists in two isoforms in mammals, $\alpha$ and $\beta$, which are only $39 \%$ identical at the amino acid level [31]. IRE1 $\alpha$ is expressed in all tissues, but IRE1 $\beta$ is only expressed in mucous cells of the respiratory and GI tracts [32]. We have shown that IRE1 $\alpha$ activation is required for cytokine production during inflammation of CF human airway epithelia [28] and CF human alveolar macrophages [30]. In contrast, activation of IRE1 $\beta$ is required for airway epithelial mucin production, and this function is specific for IRE1 $\beta$ vs. IRE1 $\alpha$ [32].

IRE1 is an ER stress sensor that contains lumenal, transmembrane and cytoplasmic regions [31]. The cytoplasmic portion of the protein contains both kinase and endoribonuclease (RNase) domains which give rise to IRE1's dual enzymatic activities. Increased ER stress triggers oligorimerization of IRE1 $\alpha$ 's inactive monomers, leading to dimerization and activation of its cytoplasmic kinase domain, resulting in a conformational change that activates its C-terminal RNase [33]. Active IRE1 $\alpha$ RNase is responsible for sequence-specific cleavage of an intron from the mRNA for the X-box binding protein-1 (XBP1) [34-36]. The cleaved XBP-1 is subsequently re-ligated by RNA $2^{\prime}, 3^{\prime}$-cyclic phosphate and $5^{\prime}-\mathrm{OH}$ ligase allowing the formation of a frame-shifted, spliced XBP-1 (XBP-1s) [37,38]. Importantly, XBP-1s translates into a transcription factor that up-regulates the lipid constituents and protein folding capacity of the ER, which are necessary for ER/ $\mathrm{Ca}^{2+}$ store expansion in inflamed airway epithelia exhibiting a robust inflammatory response [27,29]. In fact, we have previously shown that activation of IRE $1 \alpha$-dependent XBP-1s mediates airway cytokine production/secretion in models relevant to CF [22,27-30]. A review of the molecular pathways involved in IRE1 $\alpha / \mathrm{XBP}-1$ s signaling relevant to $\mathrm{CF}$ airway inflammation can be found in [27].

Our previous findings led to the notion that IRE $1 \alpha$ is a novel therapeutic target for $\mathrm{CF}$ airway inflammation. Therefore, in the present study we tested whether pharmacological inhibition of IRE1 $\alpha$ decreases cytokine production in a pre-clinical inflammatory model for CF consisting of mucosal exposure of well-differentiated primary cultures of F508del homozygous human bronchial epithelia (HBE) to supernatant of mucopurulent material (SMM) harvested from excised human CF lungs [22,39]. In addition, we tested whether a triple combination of CFTR modulators currently used in the clinic affects SMMinduced IRE1 $\alpha$ activation coupled with cytokine production in presence or absence of pharmacological inhibition of IRE1 $\alpha$. 


\section{Results}

\subsection{IRE1 $\alpha$ mRA and Protein Expression Levels Are Up-Regulated in CF Human} Airway Epithelia

We first assessed the mRNA levels of ERN1/IRE1 $\alpha$ in freshly isolated HBE from normal and inflamed CF airways. We found that ERN1/IRE1 $\alpha$ mRNA expression is upregulated in CF HBE (Figure 1A). We next evaluated by confocal microscopy whether the increased mRNA expression of IRE1 $\alpha$ in freshly isolated CF HBE corresponded to an increased expression of IRE1 $\alpha$ protein in native CF HBE. Figure 1B illustrates that IRE1 $\alpha$ protein expression is up-regulated in native CF HBE as compared with normal HBE. Notably, in both normal and CF native HBE, the expression of IRE1 $\alpha$ is polarized towards the apical domain of the epithelia (Figure 1B). Because IRE1 $\alpha$ is an ER resident protein, and is a marker of this organelle, these findings are also in agreement with our previous observations that the ER network extends towards the apical domain of airway epithelia and is expanded in inflamed CF airways [26]. Quantification of the IRE1 $\alpha$ immunostain confirmed the IRE1 $\alpha$ up-regulation in CF vs. normal native HBE (Figure 1C).

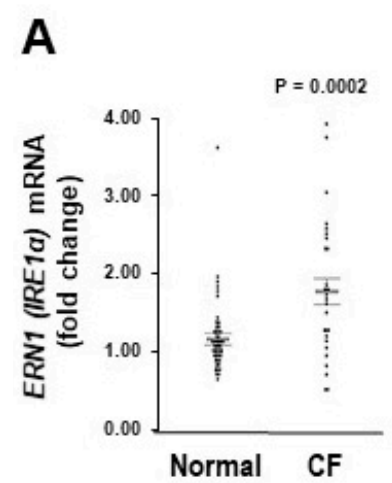

B

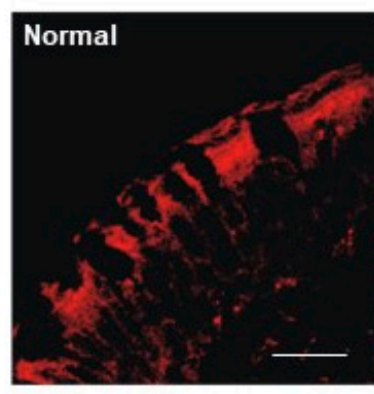

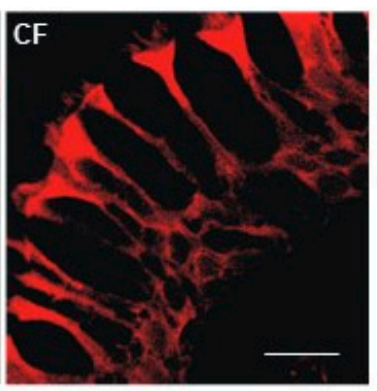

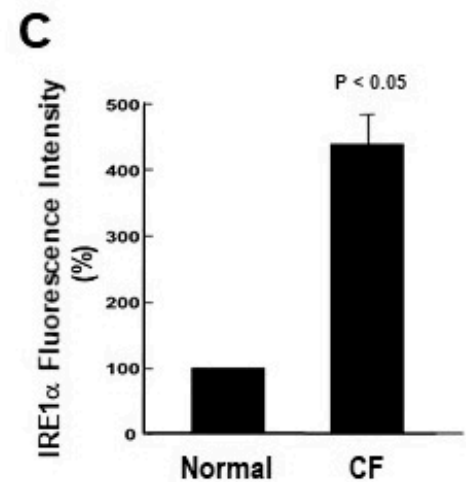

Figure 1. ERN1/IRE1 $\alpha$ mRNA and protein expression is up-regulated in freshly isolated and native CF HBE. (A): Freshly isolated HBE from 41 normal and 28 CF lungs [mRNA fold change relative to TATA-box binding protein (TBP)]; dots correspond to individual lung samples. (B): Immunofluorescent stain of IRE1 $\alpha$ expression in native HBE; representative images from 3 normal and 3 CF lungs; bars: $10 \mu \mathrm{m}$. (C): Compiled data from IRE1 $\alpha$ expression in native normal and CF HBE (expressed as percentage of fluorescence intensity from normal native HBE). (A,C): Mean \pm SEM. A and C: $p$ values indicate the comparisons between CF vs. normal samples.

\subsection{The Up-Regulation of IRE1 $\alpha$ and XBP-1s Found in Freshly Isolated CF HBE Is Reproduced in Primary Normal HBE Cultures Exposed to SMM}

We have reported that freshly isolated, inflamed CF HBE exhibit higher levels of XBP-1s [28]. These findings are associated with the up-regulation of IRE1 $\alpha$ expression in freshly isolated or native CF HBE (Figure 1), and indicate that the activities of IRE1 $\alpha$ kinase and RNase are increased in inflamed CF HBE. To address whether the increased levels of IRE1 $\alpha$ and XBP-1s in CF HBE result from an acquired response to airway inflammation, we utilized a model developed in our laboratory consisting of exposure of normal HBE devoid of CFTR mutations to SMM from human CF airways [22,28,39,40]. SMM exposure promotes HBE inflammation and triggers IRE1 $\alpha$-dependent XBP-1s-induced ER expansion linked with increased cytokine production [28]. Well-differentiated primary cultures of normal HBE were exposed to mucosal PBS (control) or SMM, and the mRNA levels of $E R N 1 / I R E 1 \alpha$ and XBP-1s were evaluated after $72 \mathrm{~h}$. SMM up-regulated ERN1/IRE1 $\alpha$ mRNA expression (Figure 2A), and this effect was associated with increased XBP-1s mRNA levels (Figure 2B). These findings indicate that (a) exposure of normal HBE to SMM reproduces the up-regulation of IRE1 $\alpha$ and XBP-1s found in inflamed, freshly isolated/native CF HBE (Figure 1; [28]) and (b) the increased expression of IRE1 $\alpha$ and XBP-1s in CF HBE reflects an acquired response to the $\mathrm{CF}$ airway milieu. 

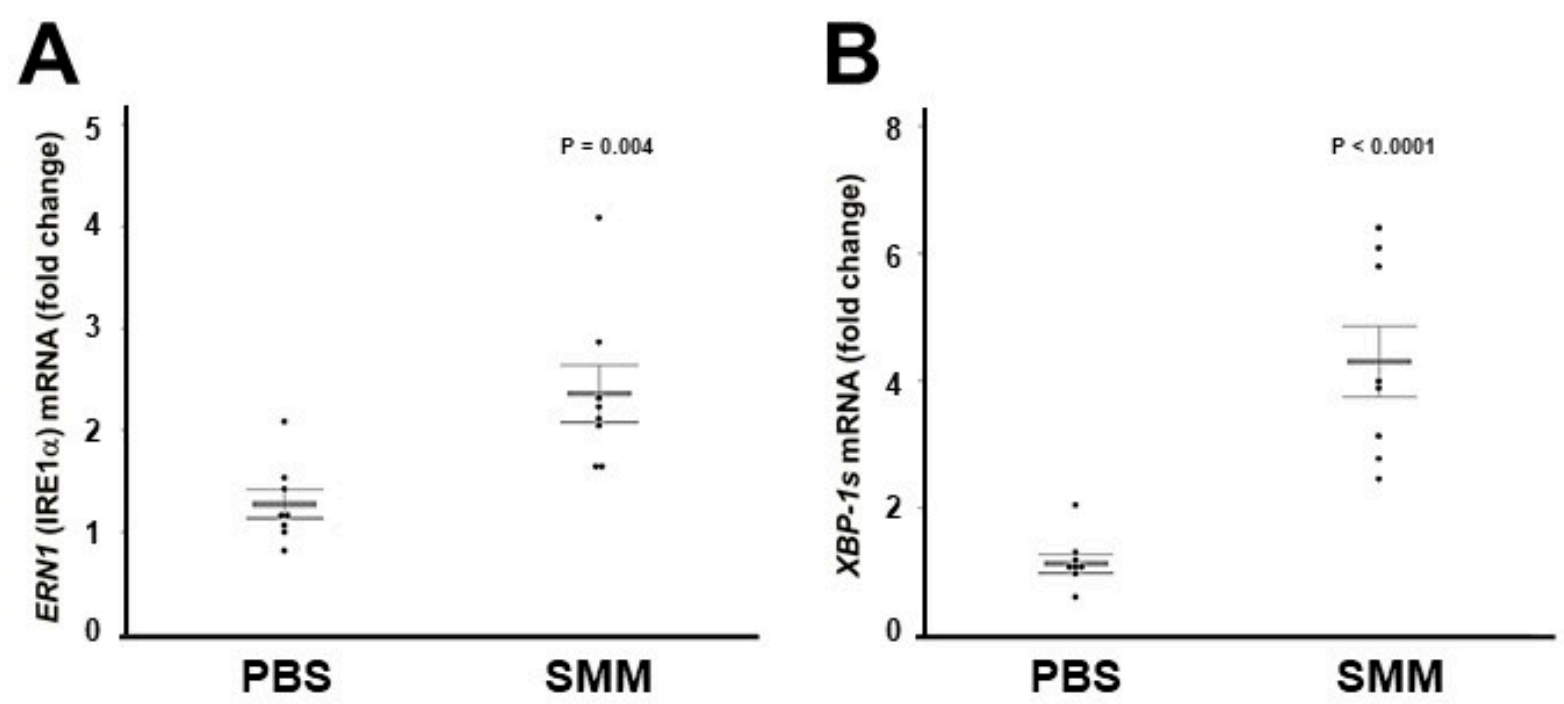

Figure 2. Mucosal exposure of normal HBE to SMM reproduces the up-regulation of ERN1/IRE1 $\alpha$ and XBP-1s mRNA levels found in inflamed, freshly isolated or native CF HBE. ERN1 (A) and XBP-1s (B) mRNA expression from PBS- or SMM-exposed cultures. Data are from $72 \mathrm{~h}$ mucosal HBE exposure to PBS or SMM, and relative to 18S mRNA. Data are shown as mean \pm SEM. $\mathrm{n}=8$ normal lungs. $p$ Values depict the comparisons between SMM- vs. PBS-exposed cultures.

\subsection{The Small Molecule IRE1 $\alpha$ Kinase and RNase Inhibitor KIRA6 (Kinase Inhibiting RNase Attenuating 6) Binds Directly to IRE1 $\alpha$ Kinase}

We evaluated the ability of the IRE1 $\alpha$ kinase and RNase inhibitor KIRA6 [41] to inhibit IRE1 $\alpha$-dependent cytokine production. KIRA 6 was selected because of its commercial availability and its type II kinase inhibitor profile. KIRA6 is a nanomolar ATP-competitive inhibitor that locks the IRE1 $\alpha$ kinase in an inactive (DFG-out), monomeric state that results in an allosteric attenuation of the RNase activity [41]. Interestingly, opposing actions for type I versus type II kinase inhibitors on the IRE1 $\alpha$ RNase have been previously described [42]. While type I inhibitors promote IRE1 $\alpha$ oligomerization and RNase activation, type II inhibitors potentially block these actions [42]. Additionally, type II kinase inhibitors, such as KIRA6, tend to be more selective than type I inhibitors due to the DFG-out binding conformation allowing for more contacts with the catalytic site [43]. However, uncharacterized "off-target" activities cannot be excluded at higher concentrations. In fact, a report suggests that KIRA6 may also inhibit Kit kinase, but only at higher doses $\left(K_{\mathrm{d}}=10.8 \mu \mathrm{M}\right)$ [44]. The structural formula of KIRA6 is depicted in Figure 3A [45]. To confirm that KIRA6 binds directly to the kinase domain of full-length cytoplasmic IRE1 $\alpha$, we utilized a TR-FRET assay that measures the displacement of a fluorescent ligand, 236, from the isolated, His-tagged IRE1 $\alpha$ kinase bound to a Europium-labeled anti-His antibody (ThermoFisher; Figure 3B). When 236 binds the ATP binding site of the IRE1 $\alpha$ kinase, there is a high degree of FRET from the Europium to the Alexa Fluor ${ }^{\mathrm{TM}}$, resulting in a high ratio of Alex Fluor to Europium signal. By design, displacement of 236 binding by an IRE1 $\alpha$ kinase inhibitor causes the FRET signal to diminish. KIRA6 dose-dependently displaced the binding of 236 from the IRE1 $\alpha$ kinase in our TR-FRET assay, with an apparent $K_{\mathrm{d}}$ of $0.28 \mu \mathrm{M}$ (Figure $3 \mathrm{C}$ ). 
A<smiles>CC(C)(C)c1nc(-c2ccc(NC(=O)Nc3cccc(C(F)(F)F)c3)c3ccccc23)c2c(N)nccn12</smiles>

B

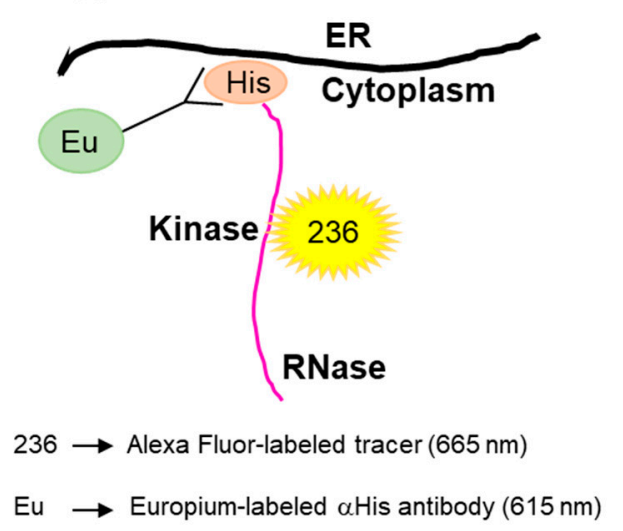

C

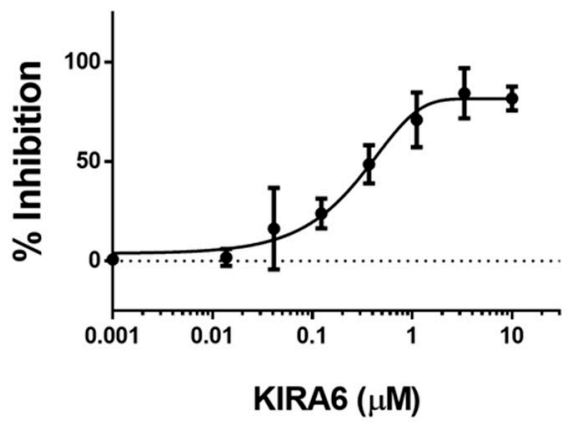

Figure 3. TR-FRET assay to evaluate the binding of KIRA6 to IRE1 $\alpha$ kinase. (A): Structure of KIRA6 (CAS No: 1589527-65-0). (B): Schematic principle of the TR-FRET assay designed to evaluate KIRA6 binding to the kinase domain of full-length cytoplasmic IRE1 $\alpha$. (C): KIRA6 binds purified IRE1 $\alpha$ kinase with an apparent $K_{\mathrm{d}}$ of $0.28 \mu \mathrm{M}$ (GraphPad Prism). The FRET response signal (ratio $665 \mathrm{~nm} / 615 \mathrm{~nm}$ ) was normalized to $\% \%=$ vehicle and $100 \%=$ inhibition with $10 \mu \mathrm{M} \mathrm{CTx}-0294885$ (positive control). Data represent mean \pm SEM ( $n=3$ separate assays).

2.4. Proof-of-Concept That Pharmacological Inhibition of IRE1 $\alpha$ Kinase and RNase Blocks XBP-1s Expression Coupled to Cytokine Production in CF HBE

Since binding of KIRA 6 to the IRE $1 \alpha$ kinase should result in attenuation of the IRE1 $\alpha$ RNase-dependent generation of XBP-1s [41,42], we conducted studies in primary F508del homozygous HBE cultures mucosally exposed to PBS or SMM, in presence or absence of various doses of KIRA6, to evaluate whether KIRA6 can attenuate IRE1 $\alpha$-driven cytokine production. We first evaluated the mRNA levels of XBP-1s, interleukin (IL)- 6 and IL-8 after $24 \mathrm{~h}$ with the various treatments. In agreement with previous studies [22,27-30], SMM up-regulated XBP-1s mRNA expression, and this response was associated with SMM-induced up-regulation of the mRNA levels of the cytokines IL-6 and IL-8 (Figure 4). However, SMM-increased XBP-1s, IL-6 and IL-8 mRNA levels were blunted, in a dosedependent manner, by KIRA6 (Figure 4). In PBS-exposed CF HBE, KIRA6 dampened the XBP-1s mRNA levels, but it did not promote inhibition of IL-6 or IL-8 mRNA expression (Figure 4).

We next evaluated whether the inhibitory effect of KIRA6 on SMM-up-regulated IL-6 and IL-8 mRNA corresponded to inhibition of SMM-increased IL-6 and IL-8 secretion. Primary F508del homozygous HBE cultures were mucosally exposed to PBS or SMM for $72 \mathrm{~h}$, in presence or absence of various doses of KIRA6. SMM increased the secretion of IL-6 and IL-8 (Figure 5A,B), in agreement with our previous findings [22,27]. KIRA6 dosedependently decreased these responses (Figure 5A,B), while in PBS-exposed CF cultures, KIRA6 did not significantly inhibit IL-6 or IL-8 secretion (Figure 5A,B). 

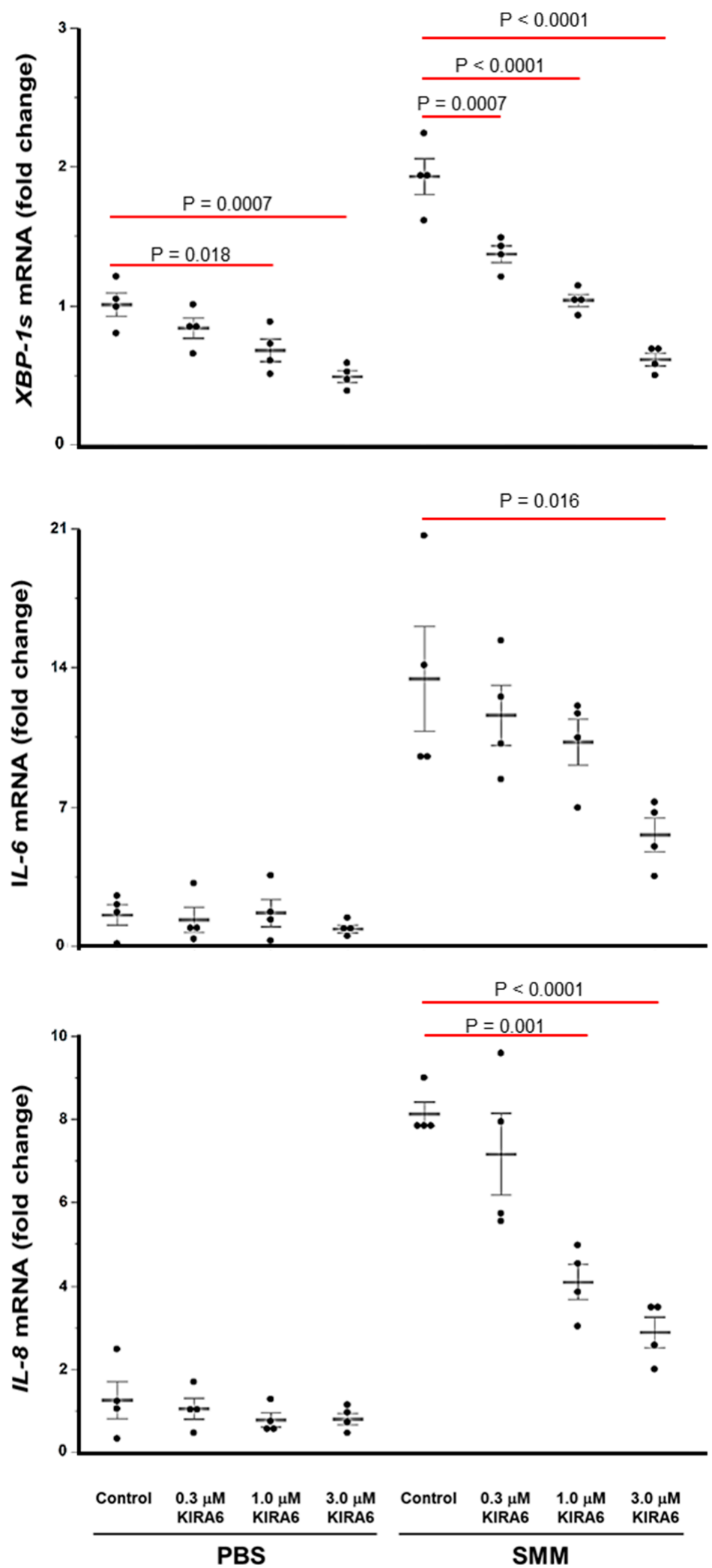

Figure 4. Inhibition of IRE $1 \alpha$ kinase and RNase with KIRA6 blunts, in a dose-dependent manner, SMM-up-regulated XBP-1s, IL-6 and IL- 8 mRNA levels in primary cultures of F508del HBE. Data are expressed as fold change over 18S, and shown as mean \pm SEM. $\mathrm{n}=4$ CF lungs. $p$ Values depict statistical differences between specific groups. 

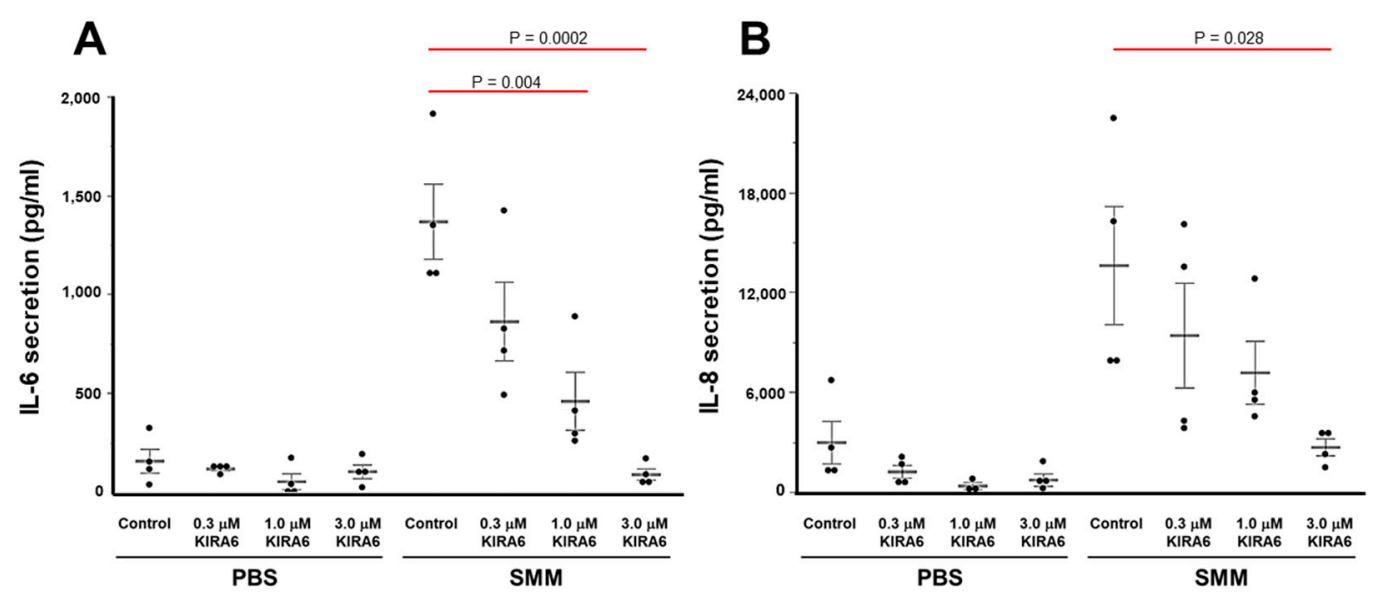

Figure 5. KIRA6 blunts, in a dose-dependent manner, SMM-increased IL-6 and IL-8 secretion in primary cultures of F508del HBE. IL-6 (A) and IL-8 (B) secretion is expressed as pg cytokine secretion/mL of culture media, and shown as mean \pm SEM. $\mathrm{n}=4$ CF lungs. $p$ Values depict statistical differences between specific groups.

\subsection{A Triple Combination of CFTR Modulators Does Not Blunt SMM-Increased XBP-1s and Cytokine Production in CF HBE}

Trikafta ${ }^{\circledR}$ [triple CFTR modulator therapy with elexacaftor (VX-445), tezacaftor (VX661), and ivacaftor (VX-770)] has been approved by the FDA for the treatment of CF patients aged 12 years and older who have at least one copy of the F508del mutation. We tested the effect of this triple therapy on SMM-up-regulated XBP-1s and IL-8 mRNA levels in primary cultures of homozygous F508del HBE. While the triple therapy effectively rescued F508del CFTR (data not shown), it did not decrease basal (PBS-treated) or SMM-upregulated XBP-1s and IL-8 mRNA levels (Figure 6A,B). Moreover, while KIRA6 inhibited SMM-increased XBP-1s and IL-8 mRNA levels, the triple CFTR modulator therapy had no effect on the inhibitory action of KIRA6 (Figure 6A,B). These findings indicate that this triple combination of CFTR modulators currently used in the clinic does not blunt SMMpromoted generation of XBP-1s coupled to IL-8 production, whereas inhibition of IRE1 $\alpha$ with KIRA6 does. In addition, our data further suggest that airway inflammation, but not CFTR dysfunction, is responsible for increased CF airway epithelial cytokine production coupled to activation of IRE $1 \alpha /$ XBP-1s signaling.

A

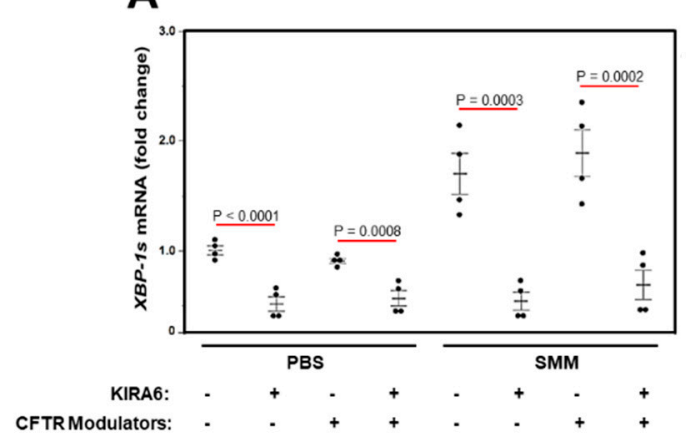

B

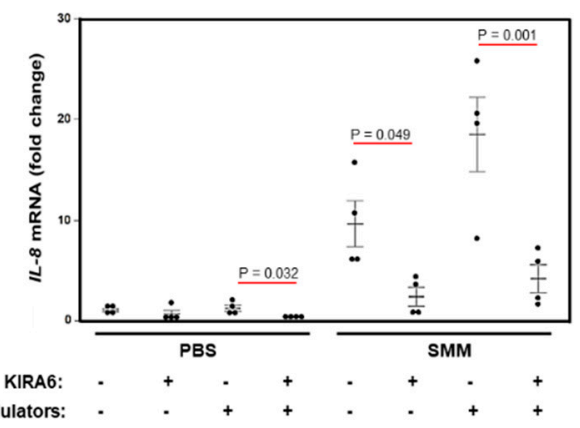

Figure 6. A triple combination of CFTR modulators does not decrease SMM-promoted generation of XBP-1s coupled to IL-8 production in F508del/F508del HBE. (A,B): Cultures were treated for $48 \mathrm{~h}$ with mucosal PBS or SMM, and serosal vehicle (DMSO) or $3 \mu \mathrm{M}$ VX-661 + $2 \mu \mathrm{M}$ VX-445 + $1 \mu \mathrm{M}$ VX-770, in the absence or presence of $3 \mu \mathrm{M}$ KIRA6. Data are expressed as fold change of XBP-1s (A) or $I L-8$ (B) mRNA levels over 18S, and shown as mean \pm SEM. $\mathrm{n}=4$ cultures from 2 CF lungs. $p$ Values depict statistical differences between specific groups. 


\section{Discussion}

Although the chronic inflammatory status of $\mathrm{CF}$ airways is associated with increased morbidity and mortality [46], conventional anti-inflammatory therapies have not proven ideal and possess adverse effects. For instance, the use of oral corticosteroids may lead to glucose intolerance, growth retardation and cataracts. Therefore, the CF Foundation recommends against the chronic use of oral corticosteroids to improve lung function in CF children [47,48]. Moreover, oral corticosteroids do not improve lung function in adults with $\mathrm{CF}$, and there is concern that their chronic use may lead to steroid-related diabetes mellitus and osteoporosis. Similarly, because inhaled corticosteroids have not proven beneficial towards improving lung function or reducing hospitalizations, the CF Foundation does not recommend their use in CF patients who do not suffer from asthma or allergic bronchopulmonary aspergillosis [47,48]. Nonsteroidal anti-inflammatory drugs, e.g., ibuprofen, are better tolerated. However, although oral ibuprofen therapy has been associated with a slower decline in $\mathrm{FEV}_{1}$, particularly in younger $\mathrm{CF}$ patients [49], and chronic ibuprofen use has been linked to improved survival [50], this therapy can lead to adverse effects such as gastrointestinal bleeding and ulcers and kidney injury. The macrolide antibiotic azithromycin has anti-inflammatory properties [51], can improve lung function [52] and is recommended for CF patients of six years and older chronically infected with $P$. aeruginosa [53]. However, its long-term treatment may result in macrolideresistant infection. The recently approved CFTR modulators are showing clinical benefits. However, solid data on their possible anti-inflammatory effect are not available yet. Based on these considerations, there is a clear unmet medical need for new therapies for CF airways inflammation.

Previous studies indicated that $\mathrm{CF}$ airway inflammatory responses are linked with activation of the IRE1 $\alpha$ pathway. Specifically, the levels of XBP-1s are increased in freshly isolated CF vs. normal airway epithelia [28]. This alteration can be reproduced in translational models relevant to CF airways disease, further linking activation of IRE1 $\alpha$ to CF airway inflammatory responses $[27,28]$. For instance, we have shown that exposure of airway epithelia to SMM up-regulates the levels of XBP-1s and this response is linked with an increased secretion of cytokines [22,27]. Furthermore, while XBP-1s levels are increased in inflamed CF HBE, they revert to normal levels in primary CF HBE cultures that have lost their excessive inflammatory response [54]. Notably, these studies also indicated that the increased levels of XBP-1s found in inflamed CF airway epithelia are not linked to CFTR mutations [22,27,54]. In addition, the functional role of IRE1 $\alpha / \mathrm{XBP}-1 \mathrm{~s}$ signaling has been subsequently extended to primary cultures of $\mathrm{CF}$ alveolar macrophages by showing that they exhibit an exaggerated production of cytokines, which is mediated by IRE1 $\alpha$-dependent XBP-1s [30]. A previous study from our group evaluated the mRNA levels of IRE1 $\alpha$ (ERN1) and IRE1 $\beta$ (ERN2) by RNAscope in proximal to terminal airway epithelia from normal vs. CF subjects [55]. Our findings indicated that while the expression of IRE1 $\alpha$ and IRE1 $\beta$ is increased in CF, the tissue expression of IRE1 $\alpha$ is more generalized, in contrast to the restricted expression of IRE1 $\beta$ to the epithelial layer. Together, these previous findings led to the notion that inhibition of IRE1 $\alpha$ might provide a new therapeutic strategy for controlling the excessive inflammation of $\mathrm{CF}$ airways by targeting the activity of this ER stress protein in multiple cell types.

The current paradigm is that the IRE1 $\alpha$ kinase is an allosteric modulator of the IRE1 $\alpha$ RNase activity and, thus, regulates the levels of XBP-1 mRNA splicing [33]. When ER stress occurs resulting from, e.g., increased ER levels of newly synthesized unfolded cytokine proteins, it causes IRE1 $\alpha$ dimerization and trans-autophosphorylation of the cytoplasmic kinase domain, leading to a conformational change that activates the RNase and allows each RNase dimer to dock a XBP-1 mRNA hairpin loop, promoting the formation of the transcription factor XBP-1s [33,56]. While RNase inhibitors have been described, such as the aldehyde-containing 4-methyl umbelliferone 8-carbaldehyde (4 $\mu 8 \mathrm{C})$ and STF-083010, that can prevent this docking, thereby reducing XBP-1 splicing and downstream XBP-1s- 
dependent signaling $[36,57,58]$, micromolar potencies and 'druggability' issues limit the clinical utility of these covalent modifiers.

The majority of IRE1 $\alpha$ kinase inhibitor ligands that have been reported, such as the type I ATP competitive kinase inhibitors CTx-0294885 [59] and Sunitinib, promote IRE1 $\alpha$ RNase dimerization, leading to increased RNase-directed mRNA splicing of XBP-1 [33]. Feldman et al. have identified 15 of these IRE1 $\alpha$ RNase activating, kinase inhibiting ligands from a Selleckchem kinase inhibitor library [60]. However, like CTx-0294885, these tend to be non-selective for other kinases and are not suitable for comparison experiments pairing dual kinase/RNase inhibitors with kinase inhibitors that activate the RNase. Far less common are the IRE1 $\alpha$ kinase inhibitors termed KIRAs [42,60]. These inhibitors block both the kinase and RNase activities of IRE1 $\alpha$, likely by preventing dimerization, and have more favorable selectivity profiles $[42,60]$.

The present study tested the premise that pharmacological inhibition of the IRE $1 \alpha \mathrm{ki}$ nase and RNase with KIRA6 could be used to ameliorate the robust inflammatory response characteristic of CF airways. Our findings can be summarized as follows. (1) IRE1 $\alpha$ expression is up-regulated in freshly isolated and native CF bronchial epithelia (Figure 1). (2) The increased IRE1 $\alpha$ levels found in CF airway epithelia can be reproduced in vitro in normal HBE exposed to SMM (Figure 2), indicating that this is an acquired response induced by the inflammatory CF airway milieu. Further, (3) inhibition of IRE1 $\alpha$ kinase and RNase activities with KIRA6 blunts SMM-increased cytokine production in CF HBE (Figures 4 and 5). The pre-clinical model consisting of primary cultures of homozygous F508del CF HBE grown at air-liquid interface [22] and exposed to SMM harvested from the airways of excised human CF lungs $[22,28,39,40]$ was utilized because it recapitulates several aspects of CF airway epithelial inflammation [22,27,28,39,40]. SMM provides an "all-inclusive" stimulus representative of the CF airway milieu because it contains (1) products from bacteria, factors from neutrophils, including neutrophil elastase, lysozyme, cathepsin G, and MMP9 [39]; (2) secretory products from airway epithelia and macrophages, including cytokines [39]; and (3) hundreds of peptides, mucins and purines [61]. The inflammatory composition of SMM is reproducible from patient to patient [39]. Because the airway epithelia of CF patients are exposed to the combination of all these inflammatory factors, the use of SMM is a superior approach vs. the use of single inflammatory factors for testing the efficacy of small molecule inhibitors of IRE1 $\alpha$ as anti-inflammatory therapeutics.

While novel anti-inflammatory therapies for CF lung disease devoid of adverse effects are necessary, care needs to be exercised to avoid decreasing the inflammatory response beyond a minimal level required for controlling bacterial infections [62]. An important aspect of the present study is that KIRA6 did not decrease the levels of cytokine production/secretion beyond the basal levels measured in the absence of SMM (Figures 4 and 5). Instead, our findings indicated that KIRA6 blunted only the excessive inflammatory component resulting from SMM exposure, which under chronic, persistent conditions, is expected to promote damage of CF airways.

An important aspect of our study is the finding that the triple CFTR modulator therapy consisting of VX-445, VX-661, and VX-770 did not blunt basal or SMM-up-regulated XBP-1s coupled with increased IL-8 production, whereas KIRA6 did (Figure 6). In agreement with these observations, recent studies from our group demonstrated that different combinations of CFTR modulators (e.g., VX-661, VX-661 + VX-770, VX-809, VX-809 + VX-770, VX-659, VX-659 + VX-770, VX-661 + VX-659, and VX-661 + VX-659 + VX-770) were devoid of an anti-inflammatory effect on SMM-exposed F508del HBE cultures [63]. Considering the contribution of CF airway epithelia to the robust cytokine levels of CF airways [27], our data indicate that a high CF airway inflammatory status may remain problematic in presence of currently available CFTR modulators. Consistent with this view, airway inflammation in CF patients with the G551D mutation was not reduced by the CFTR potentiator VX-770 in spite of improvements in other clinical parameters [64,65], although decreases in airway inflammation were reported in another study [66]. Our findings lead to the notion that 
CFTR modulators may be used in combination with IRE1 $\alpha$ inhibitors to simultaneously achieve airway hydration and decreased airway inflammation.

It should be noted that IRE $1 \alpha$ can also act in a XBP-1s-independent manner. For instance, ER stress-induced IRE1 $\alpha$ activation can recruit tumor necrosis factor receptor associated factor 2 (TRAF2) to its cytoplasmic kinase domain [67]. TRAF2 activates protein kinases involved in immunity and inflammation, including apoptosis signalregulating kinase-1 (ASK1), which in turn activates cJUN $\mathrm{NH}_{2}$-terminal kinase (JNK) and p38 mitogen-activated protein kinase (MAPK) [68]. IRE1 $\alpha$ kinase can also activate NF- $\mathrm{KB}$ via TRAF2 $[69,70]$. Because activation of these pathways can mediate inflammatory responses [27], we speculate that activation of the IRE1 $\alpha$ kinase may also lead to cytokine production in CF airways independent of IRE1 $\alpha$ RNase activation. Future studies will be necessary to tease out the relative contributions of the IRE1 $\alpha$ kinase via XBP-1s-dependent vs independent regulation of inflammatory responses in CF airways. Further, the selectivity of KIRA6 may need further refinement, as a new report found KIRA6 can induce a marker of autophagy in Neuro2a cells independent of IRE1 $\alpha$ [71]. Nevertheless, our present study suggests that IRE1 $\alpha$ plays a significant role in the excessive cytokine production of CF airways, and that small molecule inhibition of IRE1 $\alpha$ kinase with a compound that allosterically also blunts RNase activity may have clinical utility.

In conclusion, our findings lead to the model depicted in Figure 7. Airway inflammation induces ER stress and triggers the unfolded protein response in CF airway epithelia. This results in activation of the IRE $1 \alpha$ kinase and RNase activities, leading to the mRNA splicing of XBP-1. The resulting XBP-1s is a transcription factor that up-regulates cytokine production in inflamed CF airway epithelia. Our data provide the proof-of-concept that small molecule IRE1 $\alpha$ kinase inhibitors like KIRA6 that allosterically reduce RNasedependent XBP-1 mRNA splicing may lead to a novel approach for treating the excessive inflammation characteristic of $\mathrm{CF}$ airways.

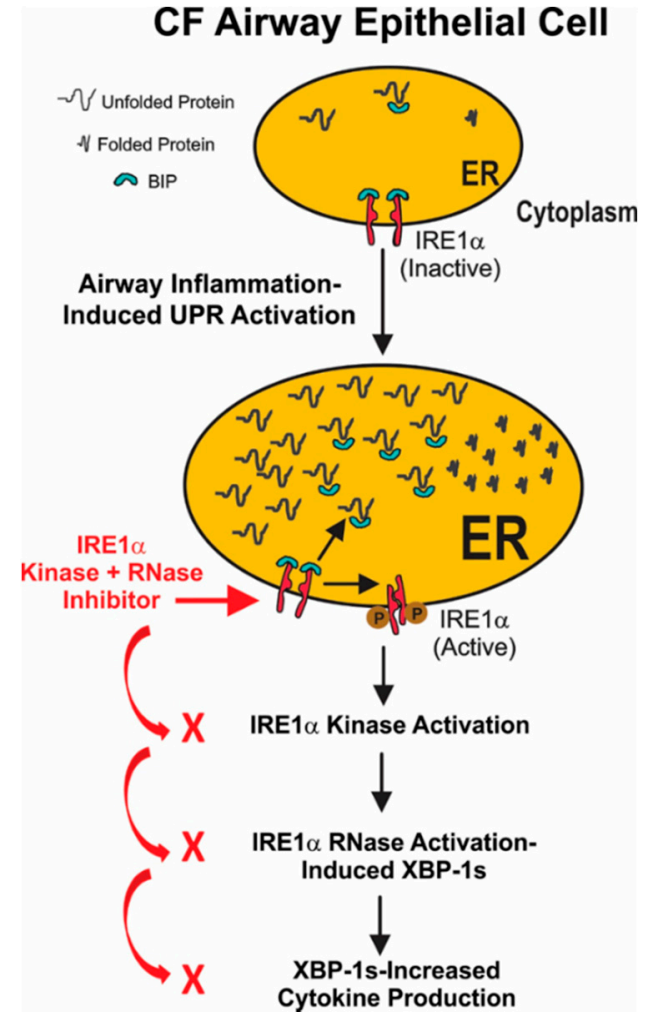

Figure 7. Model for IRE1 $\alpha$ activation-dependent cytokine production in inflamed CF airway epithelia. Airway inflammation induces ER stress and triggers the unfolded protein response in CF airway epithelia. The current notion is that under normal conditions the immunoglobulin binding protein (BIP; also known as glucose-regulated protein 78, GRP-78) binds to the ER lumenal domain of IRE1 $\alpha$, 
repressing its activation. However, following ER stress, BIP dissociation from IRE1 $\alpha$ results in activation of the IRE1 $\alpha$ kinase and RNase, leading to the mRNA splicing if XBP-1 (XBP-1s). The resulting $\mathrm{XBP}-1 \mathrm{~s}$ is a transcription factor that up-regulates cytokine production in inflamed $\mathrm{CF}$ airway epithelia. Inhibition of IRE1 $\alpha$ kinase and RNase activities with a small molecule like KIRA6 decreases $\mathrm{XBP}-1$ s levels, blunting $\mathrm{XBP}-1$ s-mediated cytokine production, thereby ameliorating $\mathrm{CF}$ airway inflammation.

\section{Materials and Methods}

\subsection{Tissue Harvesting}

Human bronchial epithelial (HBE) cells were obtained from normal and CF bronchi according to protocols approved by the University of North Carolina Biomedical Institutional Review Board (study \#18-1031, approved on 4/20/2018). Both cell types were isolated from excised lungs (e.g., for normal cells, lungs rejected for transplant by local and distant organ procurement agencies; for CF cells, lungs excised at the time of a transplant). Normal lungs originated from subjects with no history of inflammatory or infectious disease known to affect the respiratory airways. For some studies, sections from paraffin-embedded native normal and CF bronchial tissues were used. Cells and native tissues were provided by the Tissue Procurement and Cell Culture Core from the Cystic Fibrosis Research Center at the University of North Carolina at Chapel Hill as previously described [22,26,39].

\subsection{Supernatant of Mucopurulent Material (SMM) from CF Airways}

Mucopurulent material was harvested from the airway lumens of excised human CF lungs as previously reported [22,26,39], and was provided by the UNC CF Center Tissue Procurement and Cell Culture Core. Briefly, the mucopurulent material was centrifuged at $100,000 \mathrm{rpm}$ for $60 \mathrm{~min}$ at $4{ }^{\circ} \mathrm{C}$ and the resulting supernatant (SMM) was filtered with a $0.2 \mu \mathrm{m}$ filter. SMM was pooled from several CF lungs, aliquoted into single use tubes and stored at $-80{ }^{\circ} \mathrm{C}$.

\subsection{Cell Culture and Treatments}

Primary normal HBE (for studies mimicking the CF phenotype, as described in Figure 2) or F508del homozygous CF HBE were grown for 28 days and studied as polarized, well-differentiated cultures under airway liquid interface conditions, as previously described [22,26,39]. Cultures were exposed to $30 \mu \mathrm{L}$ mucosal PBS or SMM for various amounts of time in presence or absence of the IRE1 $\alpha$ kinase and RNase inhibitor, Kinase Inactivating RNase Attenuating 6 (KIRA6, CAS No.: 1589527-65-0 [41]; EMD Millipore, Burlington, MA, USA), which was added to the serosal compartment, as detailed in the figure legends.

To evaluate the effect of a triple combination of CFTR modulators on SMM-up-regulated XBP-1s coupled to IL-8 production, primary cultures of F508del/F508del HBE were treated for $48 \mathrm{~h}$ with mucosal PBS or SMM, and serosal vehicle (DMSO) or $3 \mu \mathrm{M}$ tezacaftor (VX-661, Selleck Chemicals) $+2 \mu \mathrm{M}$ elexacaftor (VX-445, MedChemExpress) $+\mu \mathrm{M}$ ivacaftor (VX-770, Selleck Chemicals, Houston, TX, USA), in the absence or serosal presence of $3 \mu \mathrm{M}$ KIRA6.

\subsection{Immunofluorescence and Quantification of IRE1 $\alpha$ Expression}

The immunostaining of IRE1 $\alpha$ in $4 \%$ paraformaldehyde-fixed and deparaffinized native bronchial epithelial sections from normal and CF lungs was performed according to a modification of our previous method [26]. All incubations and washes between steps were performed with PBS. Sections were permeabilized with $1 \%$ Triton X-100 for $10 \mathrm{~min}$ at room temperature, rinsed three times, blocked with $3 \%$ bovine serum albumin for $30 \mathrm{~min}$ at $37^{\circ} \mathrm{C}$, and washed three times. Sections were subsequently incubated overnight at $4{ }^{\circ} \mathrm{C}$ with a goat polyclonal IRE1 $\alpha$ primary antibody (1:100 dilution; Santa Cruz Biotechnology, Dallas, TX, USA), followed by three washes and incubation with a Texas Red-labeled don- 
key anti-goat antibody (1:200 dilution; Jackson Immunoresearch Laboratories, West Grove, PA, USA) for $1 \mathrm{~h}$ at room temperature. Sections were subsequently washed three times and mounted with a coverslip. As a control, the primary antibody was omitted. The fluorescent signals were studied by laser confocal microscopy (Leica, model TCS 4D; PL APO $63 \times / 1.20 \mathrm{~mm}$ water lens) in the $X Y$ scanning mode. The quantification of the fluorescence intensity of labeled IRE1 $\alpha$ was performed according to a previous method [26] utilizing the MetaMorph ${ }^{\circledR}$ Microscopy Automation and Image Analysis software. The same acquisition parameters (e.g., laser power, contrast, brightness and pinhole value) were employed to acquire the images from native normal and $\mathrm{CF}$ bronchial epithelia in experiments performed on the same day.

\subsection{Real Time Polymerase Chain Reaction (RT-PCR)}

RT-PCR was used to evaluate IRE1 $\alpha$ (ERN1), XBP-1s, IL-6 and IL-8 mRNA levels, as previously described [30]. Briefly, RNA was recovered from cultures lysed in TRI reagent using the Zymo Direct-zol mini kit (R2052, Zymo Research, Irvine, CA, USA), and cDNA was made from 500 ng of RNA using the iScript cDNA synthesis kit (1708841, Bio-Rad, Hercules, CA, USA). cDNA was then diluted 1:20 and $4 \mu \mathrm{L}$ were used with $5 \mu \mathrm{L}$ SsoAdvanced Universal Probes Supermix (1725282, Biorad, Hercules, CA, USA), $0.5 \mu \mathrm{L}$ of one Taqman Probeset (ThermoFisher Scientific, Waltham, MA, USA; IL6: Hs00174131_m1, IL8: Hs00174103_m1, XBP1s: Hs03929085_g1, TBP: Hs00427620_m1, 18s: Hs99999901_s1), and DNase-free water to $10 \mu \mathrm{L}$ total volume. The samples were run on a Quant-6 RT-PCR machine with the following protocol: $95^{\circ} \mathrm{C}$ for $20 \mathrm{~s}$, followed by 40 cycles of $95^{\circ} \mathrm{C}$ for $20 \mathrm{~s}$ and $60^{\circ} \mathrm{C}$ for $20 \mathrm{~s}$. For quantification of mRNA levels, the $\Delta \mathrm{C}_{\mathrm{T}}$ value was produced by subtracting the $\mathrm{C}_{\mathrm{T}}$ value of the housekeeping gene (18 s or TBP) from the gene of interest, as reported [30].

\subsection{Expression of the Cytoplasmic Domain of IRE1 $\alpha$}

The soluble cytoplasmic portion of human IRE1 $\alpha$ containing both the serine/threonine kinase and RNase domains (residues 547-977 of accession number NP_001424) was cloned and expressed. Briefly, IRE1 $\alpha$ was expressed as N-terminal His-tagged protein in Sf9 cells using baculovirus produced from pFastBacHT (Life Technologies, Carlsbad, CA, USA). Cells were harvested after $72 \mathrm{~h}$ and cell pellets were stored at $-80^{\circ} \mathrm{C}$ until purification.

\subsection{Purification of Cytoplasmic IRE1 $\alpha$ for Kinase Assays}

Cell pellets were thawed, resuspended, and lysed in 'cytobuster' (EMD Millipore) containing protease (EDTA-free) and phosphatase inhibitor cocktails (Pierce) and $30 \mathrm{mM} \mathrm{im}$ idazole, $\mathrm{pH}$ 8.0. The resulting cell lysates were clarified and affinity purified on HisTrapFF nickel columns (GE Healthcare) using an AKTA FPLC (GE Healthcare, Marlborough, MA, USA). Bound protein was eluted in a linear gradient of elution buffer $(50 \mathrm{mM}$ sodium phosphate buffer, pH 7.2, $500 \mathrm{mM} \mathrm{NaCl}, 500 \mathrm{mM}$ imidazole). Peak fractions were run on SDS-PAGE gels and analyzed by Coomassie staining. IRE1 $\alpha$ containing fractions were pooled and concentrated in Amicon Ultra 30K cut off concentrators (EMD Millipore) and buffer was exchanged into $25 \mathrm{mM}$ HEPES, pH 7.5, $150 \mathrm{mM} \mathrm{NaCl}, 2 \mathrm{mM}$ DTT, 5\% glycerol. Protein concentration was determined by Bradford assay. Protein was aliquoted and stored at $-80{ }^{\circ} \mathrm{C}$, with additional glycerol $(25 \%$ final) added for longer term storage. This expression and purification approach has been successfully used to study IRE1 $\alpha$ kinase activity in vitro $[58,60,72]$.

\subsection{Time Resolved-Fluorescence Resonance Energy Transfer (TR-FRET) IRE1 $\alpha$ Kinase Assay}

We developed a 384 well formatted TR-FRET assay using LanthaScreen reagents (ThermoFisher) to evaluate the binding of the IRE1 $\alpha$ inhibitor KIRA6 (EMD Millipore or MedChemExpress, Monmouth Junction, NJ, USA) to the purified full-length cytoplasmic domain of IRE1 $\alpha$. We utilized a displacement assay format with a Europium-labeled antibody that recognizes the $\mathrm{N}$-terminal His tag on the IRE1 $\alpha$ cytoplasmic protein as an 
energy donor, and an Alexa Fluor ${ }^{\mathrm{TM}}$-labelled kinase ligand, 236, as the energy acceptor (ThermoFisher). CTx-0294885, a non-selective, broad spectrum kinase inhibitor, was used as a positive control for the assay (MedChemExpress). After incubating the assay mix consisting of $20 \mathrm{nM}$ his-tagged IRE1 $\alpha, 2 \mathrm{nM}$ Europium anti-his antibody, and $40 \mathrm{nM}$ 236 tracer, the TR-FRET signal ratio $(665 \mathrm{~nm} / 615 \mathrm{~nm})$ was collected using a Perkin Elmer EnVision ${ }^{\circledR}$ plate reader. Eight point compound dose curves diluted in half logs starting at $10 \mu \mathrm{M}$ were utilized to generate the data.

\subsection{Cytokine Secretion}

Quantification of IL-6 and IL-8 secretion into cultured media was performed by standard ELISA measurements in duplicate samples, and utilized reagents from R\&D Systems as we previously published [22]. These cytokines were chosen because they are predominant cytokines present in CF airways [39]. Secretion of IL-6 and IL-8 resulting from the different treatments was evaluated after $72 \mathrm{~h}$.

\subsection{Statistical Analyses}

For the native tissue and HBE studies, we performed either unpaired Student's T-test or one-way ANOVA, including standard (parametric) methods and the Tukey-Kramer multiple comparisons test [32] or the Dunnett test, utilizing the JMP Software from SAS.

Data from bar graphs or dot plots represent the mean \pm SEM and statistical significance was defined with $p<0.05$. For the TR-FRET kinase binding assays, compounds were tested in 8-point dose curves with half-log dilutions from a top concentration of $10 \mu \mathrm{M}$. GraphPad Prism6 was used to calculate 4-parameter fits of response data normalized to $100 \%$ inhibition equal to the amount of FRET signal displaced by $10 \mu \mathrm{M}$ CTx-0294885 (positive control for maximal IRE1 $\alpha$ kinase binding), and $0 \%$ equal to the vehicle control (1\% DMSO).

Author Contributions: Conceptualization, C.M.P.R.; methodology, E.A.H.-R., J.T.M., M.E.B.M., J.L.N.-D., and C.M.P.R.; validation, E.A.H.-R., J.T.M., M.E.B.M., J.L.N.-D., and C.M.P.R.; formal analysis, E.A.H.-R., J.T.M., M.E.B.M., and C.M.P.R.; resources, T.K.; writing-original draft preparation, C.M.P.R.; writing—review and editing, E.A.H.-R., T.K., and C.M.P.R.; supervision, C.M.P.R.; project administration, C.M.P.R.; funding acquisition, C.M.P.R. All authors have read and agreed to the published version of the manuscript.

Funding: This research was funded by The Cystic Fibrosis Foundation, grant number RBEIR18G0. We also acknowledge the Eshelman Institute for Innovation at the University of North Carolina at Chapel Hill for a grant (RX03512115), which supported work that led to this study.

Institutional Review Board Statement: Not applicable (this study did not involve human subjects or animals).

Informed Consent Statement: Not applicable.

Data Availability Statement: Not applicable.

Acknowledgments: We thank Scott Randell, from the Tissue Procurement and Cell Culture Core from the Cystic Fibrosis Research Center at the University of North Carolina at Chapel Hill, for providing the tissues, HBE, and mucopurulent material; Gang Chen, from the Marsico Lung Institute and Cystic Fibrosis Research Center at the University of North Carolina at Chapel Hill, for cDNA from PBS- and SMM-treated HBE; and Eric Roe, from the Cystic Fibrosis Research Center at the University of North Carolina at Chapel Hill, for editorial assistance.

Conflicts of Interest: The authors declare no conflict of interest. The funders had no role in the design of the study; in the collection, analyses, or interpretation of data; in the writing of the manuscript, or in the decision to publish the results. 


\section{References}

1. Boucher, R.C.; Cotton, C.U.; Gatzy, J.T.; Knowles, M.R.; Yankaskas, J.R. Evidence for reduced Cl- and increased Na+ permeability in cystic fibrosis human primary cell cultures. J. Physiol. 1988, 405, 77-103. [CrossRef] [PubMed]

2. Keiser, N.W.; Engelhardt, J.F. New animal models of cystic fibrosis: What are they teaching us? Curr. Opin. Pulm. Med. 2011, 17, 478-483. [CrossRef]

3. Matsui, H.; Grubb, B.R.; Tarran, R.; Randell, S.H.; Gatzy, J.T.; Davis, C.W.; Boucher, R.C. Evidence for periciliary liquid layer depletion, not abnormal ion composition, in the pathogenesis of cystic fibrosis airways disease. Cell 1998, 95, 1005-1015. [CrossRef]

4. Boucher, R.C. Evidence for airway surface dehydration as the initiating event in CF airway disease. J. Intern. Med. 2007, 261, 5-16. [CrossRef]

5. Hobbs, C.A.; Da Tan, C.; Tarran, R. Does epithelial sodium channel hyperactivity contribute to cystic fibrosis lung disease? J. Physiol. 2013, 591, 4377-4387. [CrossRef] [PubMed]

6. Mall, M.A.; Hartl, D. CFTR: Cystic fibrosis and beyond. Eur. Respir. J. 2014, 44, 1042-1054. [CrossRef]

7. Konstan, M.W.; Hilliard, K.A.; Norvell, T.M.; Berger, M. Bronchoalveolar lavage findings in cystic fibrosis patients with stable, clinically mild lung disease suggest ongoing infection and inflammation. Am. J. Respir. Crit. Care Med. 1994, 150, 448-454. [CrossRef] [PubMed]

8. Khan, T.Z.; Wagener, J.S.; Bost, T.; Martinez, J.; Accurso, F.J.; Riches, D.W. Early pulmonary inflammation in infants with cystic fibrosis. Am. J. Respir. Crit. Care Med. 1995, 151, 1075-1082. [CrossRef] [PubMed]

9. Koller, D.Y.; Nething, I.; Otto, J.; Urbanek, R.; Eichler, I. Cytokine concentrations in sputum from patients with cystic fibrosis and their relation to eosinophil activity. Am. J. Respir. Crit. Care Med. 1997, 155, 1050-1054. [CrossRef]

10. Muhlebach, M.S.; Stewart, P.W.; Leigh, M.W.; Noah, T.L. Quantitation of inflammatory responses to bacteria in young cystic fibrosis and control patients. Am. J. Respir. Crit. Care Med. 1999, 160, 186-191. [CrossRef]

11. Taggart, C.; Coakley, R.J.; Greally, P.; Canny, G.; O'Neill, S.J.; McElvaney, N.G. Increased elastase release by CF neutrophils is mediated by tumor necrosis factor-alpha and interleukin-8. Am. J. Physiol. Lung Cell. Mol. Physiol. 2000, 278, L33-L41. [CrossRef]

12. Muhlebach, M.S.; Noah, T.L. Endotoxin activity and inflammatory markers in the airways of young patients with cystic fibrosis. Am. J. Respir. Crit. Care Med. 2002, 165, 911-915. [CrossRef]

13. Elizur, A.; Cannon, C.L.; Ferkol, T.W. Airway inflammation in cystic fibrosis. Chest 2008, 133, 489-495. [CrossRef] [PubMed]

14. Ranganathan, S.C.; Parsons, F.; Gangell, C.; Brennan, S.; Stick, S.M.; Sly, P.D. Evolution of pulmonary inflammation and nutritional status in infants and young children with cystic fibrosis. Thorax 2011, 66, 408-413. [CrossRef] [PubMed]

15. Sagel, S.D.; Wagner, B.D.; Anthony, M.M.; Emmett, P.; Zemanick, E.T. Sputum biomarkers of inflammation and lung function decline in children with cystic fibrosis. Am. J. Respir. Crit. Care Med. 2012, 186, 857-865. [CrossRef] [PubMed]

16. Elborn, J.S. Cystic fibrosis. Lancet 2016, 388, 2519-2531. [CrossRef]

17. Roesch, E.A.; Nichols, D.P.; Chmiel, J.F. Inflammation in cystic fibrosis: An update. Pediatr. Pulmonol. 2018, 53, S30-S50. [CrossRef]

18. Bergeron, C.; Cantin, A.M. Cystic fibrosis: Pathophysiology of lung disease. Semin. Respir. Crit. Care Med. 2019, 40, 715-726. [CrossRef]

19. Cabrini, G.; Rimessi, A.; Borgatti, M.; Lampronti, I.; Finotti, A.; Pinton, P.; Gambari, R. Role of cystic fibrosis bronchial epithelium in neutrophil chemotaxis. Front. Immunol. 2020, 11, 1438. [CrossRef] [PubMed]

20. Prandini, P.; De Logu, F.; Fusi, C.; Provezza, L.; Nassini, R.; Montagner, G.; Materazzi, S.; Munari, S.; Gilioli, E.; Bezzerri, V.; et al. Transient receptor potential ankyrin 1 channels modulate inflammatory response in respiratory cells from patients with cystic fibrosis. Am. J. Respir. Cell Mol. Biol. 2016, 55, 645-656. [CrossRef]

21. Rimessi, A.; Bezzerri, V.; Salvatori, F.; Tamanini, A.; Nigro, F.; Dechecchi, M.C.; Santangelo, A.; Prandini, P.; Munari, S.; Provezza, L.; et al. PLCB3 loss-of-function reduces P. aeruginosa-dependent IL-8 release in cystic fibrosis. Am. J. Respir. Cell Mol. Biol. 2018, 59, 428-436. [CrossRef] [PubMed]

22. Ribeiro, C.M.; Paradiso, A.M.; Schwab, U.; Perez-Vilar, J.; Jones, L.; O'Neal, W.; Boucher, R.C. Chronic airway infection/inflammation induces a $\mathrm{Ca} 2+\mathrm{i}-d e p e n d e n t$ hyperinflammatory response in human cystic fibrosis airway epithelia. J. Biol. Chem. 2005, 280, 17798-17806. [CrossRef] [PubMed]

23. Tabary, O.; Escotte, S.; Couetil, J.P.; Hubert, D.; Dusser, D.; Puchelle, E.; Jacquot, J. High susceptibility for cystic fibrosis human airway gland cells to produce IL-8 through the I kappa B kinase alpha pathway in response to extracellular $\mathrm{NaCl}$ content. J. Immunol. 2000, 164, 3377-3384. [CrossRef]

24. Tabary, O.; Zahm, J.M.; Hinnrasky, J.; Couetil, J.P.; Cornillet, P.; Guenounou, M.; Gaillard, D.; Puchelle, E.; Jacquot, J. Selective upregulation of chemokine IL-8 expression in cystic fibrosis bronchial gland cells in vivo and in vitro. Am. J. Pathol. 1998, 153, 921-930. [CrossRef]

25. Bonfield, T.L.; Konstan, M.W.; Berger, M. Altered respiratory epithelial cell cytokine production in cystic fibrosis. J. Allergy Clin. Immunol. 1999, 104, 72-78. [CrossRef]

26. Ribeiro, C.M.; Paradiso, A.M.; Carew, M.A.; Shears, S.B.; Boucher, R.C. Cystic fibrosis airway epithelial Ca ${ }^{2+}$ i signaling: The mechanism for the larger agonist-mediated $\mathrm{Ca}^{2+}$ i signals in human cystic fibrosis airway epithelia. J. Biol. Chem. 2005, 280, 10202-10209. [CrossRef]

27. Ribeiro, C.M.; Lubamba, B.A. Role of IRE1alpha/XBP-1 in cystic fibrosis airway inflammation. Int. J. Mol. Sci. 2017, 18, 118. [CrossRef] 
28. Martino, M.E.; Olsen, J.C.; Fulcher, N.B.; Wolfgang, M.C.; O’Neal, W.K.; Ribeiro, C.M. Airway epithelial inflammation-induced endoplasmic reticulum $\mathrm{Ca}^{2+}$ store expansion is mediated by X-box binding protein-1. J. Biol. Chem. 2009, $284,14904-14913$. [CrossRef]

29. Ribeiro, C.M.; Boucher, R.C. Role of endoplasmic reticulum stress in cystic fibrosis-related airway inflammatory responses. Proc. Am. Thorac. Soc. 2010, 7, 387-394. [CrossRef] [PubMed]

30. Lubamba, B.A.; Jones, L.C.; O'Neal, W.K.; Boucher, R.C.; Ribeiro, C.M. X-box-binding protein 1 and innate Immune responses of human cystic fibrosis alveolar macrophages. Am. J. Respir. Crit. Care Med. 2015, 192, 1449-1461. [CrossRef] [PubMed]

31. Iwawaki, T.; Hosoda, A.; Okuda, T.; Kamigori, Y.; Nomura-Furuwatari, C.; Kimata, Y.; Tsuru, A.; Kohno, K. Translational control by the ER transmembrane kinase/ribonuclease IRE1 under ER stress. Nat. Cell Biol. 2001, 3, 158-164. [CrossRef] [PubMed]

32. Martino, M.B.; Jones, L.; Brighton, B.; Ehre, C.; Abdulah, L.; Davis, C.W.; Ron, D.; O'Neal, W.K.; Ribeiro, C.M. The ER stress transducer IRE1beta is required for airway epithelial mucin production. Mucosal Immunol. 2013, 6, 639-654. [CrossRef]

33. Hetz, C.; Chevet, E.; Harding, H.P. Targeting the unfolded protein response in disease. Nat. Rev. Drug Discov. 2013, 12, 703-719. [CrossRef] [PubMed]

34. Yoshida, H.; Matsui, T.; Yamamoto, A.; Okada, T.; Mori, K. XBP1 mRNA is induced by ATF6 and spliced by IRE1 in response to ER stress to produce a highly active transcription factor. Cell 2001, 107, 881-891. [CrossRef]

35. Calfon, M.; Zeng, H.; Urano, F.; Till, J.H.; Hubbard, S.R.; Harding, H.P.; Clark, S.G.; Ron, D. IRE1 couples endoplasmic reticulum load to secretory capacity by processing the XBP-1 mRNA. Nature 2002, 415, 92-96. [CrossRef] [PubMed]

36. Jiang, D.; Niwa, M.; Koong, A.C. Targeting the IRE1 $\alpha$-XBP1 branch of the unfolded protein response in human diseases. Semin. Cancer Biol. 2015, 33, 48-56. [CrossRef] [PubMed]

37. Logue, S.E.; McGrath, E.P.; Cleary, P.; Greene, S.; Mnich, K.; Almanza, A.; Chevet, E.; Dwyer, R.M.; Oommen, A.; Legembre, P.; et al. Inhibition of IRE1 RNase activity modulates the tumor cell secretome and enhances response to chemotherapy. Nat. Commun. 2018, 9, 3267. [CrossRef]

38. Lu, Y.; Liang, F.X.; Wang, X. A synthetic biology approach identifies the mammalian UPR RNA ligase RtcB. Mol. Cell 2014, 55, 758-770. [CrossRef] [PubMed]

39. Abdullah, L.H.; Coakley, R.; Webster, M.J.; Zhu, Y.; Tarran, R.; Radicioni, G.; Kesimer, M.; Boucher, R.C.; Davis, C.W.; Ribeiro, C.M.P. Mucin production and hydration responses to mucopurulent materials in normal versus cystic fibrosis airway epithelia. Am. J. Respir. Crit. Care Med. 2018, 197, 481-491. [CrossRef] [PubMed]

40. Ribeiro, C.M.; Hurd, H.; Wu, Y.; Martino, M.E.; Jones, L.; Brighton, B.; Boucher, R.C.; O’Neal, W.K. Azithromycin treatment alters gene expression in inflammatory, lipid metabolism, and cell cycle pathways in well-differentiated human airway epithelia. PLoS ONE 2009, 4, e5806. [CrossRef]

41. Ghosh, R.; Wang, L.; Wang, E.S.; Perera, B.G.; Igbaria, A.; Morita, S.; Prado, K.; Thamsen, M.; Caswell, D.; Macias, H.; et al. Allosteric inhibition of the IRE1alpha RNase preserves cell viability and function during endoplasmic reticulum stress. Cell 2014, 158, 534-548. [CrossRef]

42. Wang, L.; Perera, B.G.; Hari, S.B.; Bhhatarai, B.; Backes, B.J.; Seeliger, M.A.; Schurer, S.C.; Oakes, S.A.; Papa, F.R.; Maly, D.J. Divergent allosteric control of the IRE1alpha endoribonuclease using kinase inhibitors. Nat. Chem. Biol. 2012, 8, 982-989. [CrossRef]

43. Bhullar, K.S.; Lagarón, N.O.; McGowan, E.M.; Parmar, I.; Jha, A.; Hubbard, B.P.; Rupasinghe, H.P.V. Kinase-targeted cancer therapies: Progress, challenges and future directions. Mol. Cancer 2018, 17, 48. [CrossRef] [PubMed]

44. Mahameed, M.; Wilhelm, T.; Darawshi, O.; Obiedat, A.; Tommy, W.S.; Chintha, C.; Schubert, T.; Samali, A.; Chevet, E.; Eriksson, L.A.; et al. The unfolded protein response modulators GSK2606414 and KIRA6 are potent KIT inhibitors. Cell Death Dis. 2019, 10, 300. [CrossRef] [PubMed]

45. PubChem. PubChem Compound Summary for CID 73425700. Available online: https://pubchem.ncbi.nlm.nih.gov/compound/ kira6 (accessed on 21 January 2021).

46. McElvaney, O.J.; Wade, P.; Murphy, M.; Reeves, E.P.; McElvaney, N.G. Targeting airway inflammation in cystic fibrosis. Expert Rev. Respir. Med. 2019, 13, 1041-1055. [CrossRef]

47. Flume, P.A.; O'Sullivan, B.P.; Robinson, K.A.; Goss, C.H.; Mogayzel, P.J., Jr.; Willey-Courand, D.B.; Bujan, J.; Finder, J.; Lester, M.; Quittell, L.; et al. Cystic fibrosis pulmonary guidelines: Chronic medications for maintenance of lung health. Am. J. Respir. Crit. Care Med. 2007, 176, 957-969. [CrossRef] [PubMed]

48. Mogayzel, P.J., Jr.; Naureckas, E.T.; Robinson, K.A.; Mueller, G.; Hadjiliadis, D.; Hoag, J.B.; Lubsch, L.; Hazle, L.; Sabadosa, K.; Marshall, B. Cystic fibrosis pulmonary guidelines. Chronic medications for maintenance of lung health. Am. J. Respir. Crit. Care Med. 2013, 187, 680-689. [CrossRef] [PubMed]

49. Konstan, M.W.; Schluchter, M.D.; Xue, W.; Davis, P.B. Clinical use of Ibuprofen is associated with slower FEV1 decline in children with cystic fibrosis. Am. J. Respir. Crit. Care Med. 2007, 176, 1084-1089. [CrossRef] [PubMed]

50. Konstan, M.W.; VanDevanter, D.R.; Sawicki, G.S.; Pasta, D.J.; Foreman, A.J.; Neiman, E.A.; Morgan, W.J. Association of high-dose ibuprofen use, lung function decline, and long-term survival in children with cystic fibrosis. Ann. Am. Thorac. Soc. 2018, 15, 485-493. [CrossRef]

51. Marjanovic, N.; Bosnar, M.; Michielin, F.; Wille, D.R.; Anic-Milic, T.; Culic, O.; Popovic-Grle, S.; Bogdan, M.; Parnham, M.J.; Erakovic Haber, V. Macrolide antibiotics broadly and distinctively inhibit cytokine and chemokine production by COPD sputum cells in vitro. Pharmacol. Res. 2011, 63, 389-397. [CrossRef] 
52. Southern, K.W.; Barker, P.M.; Solis-Moya, A.; Patel, L. Macrolide antibiotics for cystic fibrosis. Cochrane Database Syst. Rev. 2012, 11, CD002203. [CrossRef] [PubMed]

53. Saiman, L.; Marshall, B.C.; Mayer-Hamblett, N.; Burns, J.L.; Quittner, A.L.; Cibene, D.A.; Coquillette, S.; Fieberg, A.Y.; Accurso, F.J.; Campbell, P.W., 3rd. Azithromycin in patients with cystic fibrosis chronically infected with Pseudomonas aeruginosa: A randomized controlled trial. JAMA 2003, 290, 1749-1756. [CrossRef] [PubMed]

54. Ribeiro, C.M.; O'Neal, W.K. Endoplasmic reticulum stress in chronic obstructive lung diseases. Curr. Mol. Med. 2012, 12, 872-882. [CrossRef]

55. Chen, G.; Sun, L.; Kato, T.; Okuda, K.; Martino, M.B.; Abzhanova, A.; Lin, J.M.; Gilmore, R.C.; Batson, B.D.; O’Neal, Y.K.; et al. IL-1beta dominates the promucin secretory cytokine profile in cystic fibrosis. J. Clin. Investig. 2019, 129, 4433-4450. [CrossRef]

56. Korennykh, A.V.; Korostelev, A.A.; Egea, P.F.; Finer-Moore, J.; Stroud, R.M.; Zhang, C.; Shokat, K.M.; Walter, P. Structural and functional basis for RNA cleavage by Ire1. BMC Biol. 2011, 9, 47. [CrossRef] [PubMed]

57. Papandreou, I.; Denko, N.C.; Olson, M.; Van Melckebeke, H.; Lust, S.; Tam, A.; Solow-Cordero, D.E.; Bouley, D.M.; Offner, F.; Niwa, M.; et al. Identification of an Ire1alpha endonuclease specific inhibitor with cytotoxic activity against human multiple myeloma. Blood 2011, 117, 1311-1314. [CrossRef] [PubMed]

58. Cross, B.C.; Bond, P.J.; Sadowski, P.G.; Jha, B.K.; Zak, J.; Goodman, J.M.; Silverman, R.H.; Neubert, T.A.; Baxendale, I.R.; Ron, D.; et al. The molecular basis for selective inhibition of unconventional mRNA splicing by an IRE1-binding small molecule. Proc. Natl. Acad. Sci. USA 2012, 109, E869-E878. [CrossRef] [PubMed]

59. Zhang, L.; Holmes, I.P.; Hochgräfe, F.; Walker, S.R.; Ali, N.A.; Humphrey, E.S.; Wu, J.; de Silva, M.; Kersten, W.J.; Connor, T.; et al . Characterization of the novel broad-spectrum kinase inhibitor CTx-0294885 as an affinity reagent for mass spectrometry-based kinome profiling. J. Proteome Res. 2013, 12, 3104-3116. [CrossRef]

60. Feldman, H.C.; Tong, M.; Wang, L.; Meza-Acevedo, R.; Gobillot, T.A.; Lebedev, I.; Gliedt, M.J.; Hari, S.B.; Mitra, A.K.; Backes, B.J.; et al. Structural and functional analysis of the allosteric inhibition of IRE1alpha with ATP-competitive ligands. ACS Chem. Biol. 2016, 11, 2195-2205. [CrossRef] [PubMed]

61. Esther, C.R., Jr.; Alexis, N.E.; Clas, M.L.; Lazarowski, E.R.; Donaldson, S.H.; Ribeiro, C.M.; Moore, C.G.; Davis, S.D.; Boucher, R.C. Extracellular purines are biomarkers of neutrophilic airway inflammation. Eur. Respir. J. 2008, 31, 949-956. [CrossRef]

62. Cantin, A.M.; Hartl, D.; Konstan, M.W.; Chmiel, J.F. Inflammation in cystic fibrosis lung disease: Pathogenesis and therapy. J. Cyst. Fibros. 2015, 14, 419-430. [CrossRef]

63. Gentzsch, M.; Cholon, D.M.; Quinney, N.L.; Martino, M.E.B.; Minges, J.T.; Boyles, S.E.; Guhr Lee, T.N.; Esther, C.R.; Ribeiro, C.M.P. Airway epithelial inflammation in vitro augments the rescue of mutant CFTR by current CFTR modulator therapies. Front. Pharmacol. 2021, 12, 628722. [CrossRef]

64. Harris, J.K.; Wagner, B.D.; Zemanick, E.T.; Robertson, C.E.; Stevens, M.J.; Heltshe, S.L.; Rowe, S.M.; Sagel, S.D. Changes in airway microbiome and inflammation with ivacaftor treatment in patients with cystic fibrosis and the G551D mutation. Ann. Am. Thorac. Soc. 2020, 17, 212-220. [CrossRef] [PubMed]

65. Rowe, S.M.; Heltshe, S.L.; Gonska, T.; Donaldson, S.H.; Borowitz, D.; Gelfond, D.; Sagel, S.D.; Khan, U.; Mayer-Hamblett, N.; Van Dalfsen, J.M.; et al. Clinical mechanism of the cystic fibrosis transmembrane conductance regulator potentiator ivacaftor in G551D-mediated cystic fibrosis. Am. J. Respir. Crit. Care Med. 2014, 190, 175-184. [CrossRef] [PubMed]

66. Hisert, K.B.; Heltshe, S.L.; Pope, C.; Jorth, P.; Wu, X.; Edwards, R.M.; Radey, M.; Accurso, F.J.; Wolter, D.J.; Cooke, G.; et al. Restoring cystic fibrosis transmembrane conductance regulator function reduces airway bacteria and inflammation in people with cystic fibrosis and chronic lung infections. Am. J. Respir. Crit. Care Med. 2017, 195, 1617-1628. [CrossRef]

67. Urano, F.; Wang, X.; Bertolotti, A.; Zhang, Y.; Chung, P.; Harding, H.P.; Ron, D. Coupling of stress in the ER to activation of JNK protein kinases by transmembrane protein kinase IRE1. Science 2000, 287, 664-666. [CrossRef]

68. Nishitoh, H.; Matsuzawa, A.; Tobiume, K.; Saegusa, K.; Takeda, K.; Inoue, K.; Hori, S.; Kakizuka, A.; Ichijo, H. ASK1 is essential for endoplasmic reticulum stress-induced neuronal cell death triggered by expanded polyglutamine repeats. Genes Dev. 2002, 16, 1345-1355. [CrossRef] [PubMed]

69. Kaneko, M.; Niinuma, Y.; Nomura, Y. Activation signal of nuclear factor-kappa B in response to endoplasmic reticulum stress is transduced via IRE1 and tumor necrosis factor receptor-associated factor 2. Biol. Pharm. Bull. 2003, 26, 931-935. [CrossRef] [PubMed]

70. Hu, P.; Han, Z.; Couvillon, A.D.; Kaufman, R.J.; Exton, J.H. Autocrine tumor necrosis factor alpha links endoplasmic reticulum stress to the membrane death receptor pathway through IRE1alpha-mediated NF-kappaB activation and down-regulation of TRAF2 expression. Mol. Cell. Biol. 2006, 26, 3071-3084. [CrossRef] [PubMed]

71. Oh-Hashi, K.; Kohno, H.; Kandeel, M.; Hirata, Y. Characterization of IRE1 $\alpha$ in Neuro2a cells by pharmacological and CRISPR/Cas9 approaches. Mol. Cell. Biochem. 2020, 465, 53-64. [CrossRef]

72. Ranatunga, S.; Tang, C.H.; Kang, C.W.; Kriss, C.L.; Kloppenburg, B.J.; Hu, C.C.; Del Valle, J.R. Synthesis of novel tricyclic chromenone-based inhibitors of IRE-1 RNase activity. J. Med. Chem. 2014, 57, 4289-4301. [CrossRef] [PubMed] 